East African Medical Journal Vol. 83 No. 1 January 2006

MILLENNIUM DEVELOPMENT GOAL 5: A REVIEW OF MATERNAL MORTALITY AT THE KENYATTA NATIONAL HOSPITAL, NAIROBI J.B.O. Oyieke, MBChB, MMed, Senior Lecturer and Chairman, Department of Obstetrics and Gynaecology, College of Health Sciences, University of Nairobi, P.O. Box 19676-00202 Nairobi, Kenya, S. Obore, MBChB (Makerere), MMed, Lecturer, Department of Obstetrics and Gynaecology, Makerere University, P.O. Box 7072, Kampala and C.S. Kigondu, PhD, Associate Professor, Department of Clinical Chemistry, College of Health Sciences, University of Nairobi, P.O. Box 19676-00202, Nairobi, Kenya

Requests for reprints to: Dr. J.B.O. Oyieke, Department of Obstetrics and Gynaecology, College of Health Sciences, University of Nairobi, P.O. Box 1967600202, Nairobi, Kenya

\title{
MILLENNIUM DEVELOPMENT GOAL 5: A REVIEW OF MATERNAL MORTALITY AT THE KENYATTA NATIONAL HOSPITAL, NAIROBI
}

\author{
J.B.O. OYIEKE, S. OBORE and C.S. KIGONDU
}

\begin{abstract}
Objectives: To review if there is a change in the maternal mortality rate at the Kenyatta National Hospital since the inception of the Millennium Development Goal strategy in 1990 , compared to earlier reviews.

Design: A retrospective descriptive study.

Setting: Kenyatta National Hospital.

Subjects: Maternal deaths attributed directly to obstetric causes.

Main outcome measures: Determination of maternal mortality rates of all patients admitted to the Kenyatta National Hospital Maternity and died after admission up till six weeks of admission. Also determine any avoidable causes of the same.

Results: During the period under review, there were 27,455 deliveries and 253 maternal deaths giving a maternal mortality ratio of 921.5 per $\mathbf{1 0 0 , 0 0 0}$ live births. Direct obstetric causes accounted for $71 \%$ of all maternal deaths with sepsis, haemorrhage, and hypertension being the leading causes. Respiratory tract infections associated with HIV/ AIDS infection was the prominent indirect cause. $67.5 \%$ of deaths occurred in women aged between 25 and 35 years and $78.7 \%$ were Para 2 or less. Evidently there was poor antenatal clinic attendance with only $28.6 \%$ having had any attendance at all. Conclusion: Antenatal clinic attendance needs to be re-emphasised if an impact is to be realised in curbing maternal mortality; moreover there is need for early referrals and encouraging mothers to deliver under skilled care.
\end{abstract}

\section{INTRODUCTION}

Worldwide, more than 50 million women suffer the consequences of poor reproductive health care such as serious pregnancy related illnesses and disability. Every year close to 500,000 women die from complications of pregnancy and childbirth, majority of who come from the developing world. Looked at in a different way, whereas one in every 16 women will die of pregnancy complications in the developing countries, only one in 2,800 will die of similar problems in the developed countries. Almost all (95\%) of these yearly maternal deaths occur in sub-Saharan Africa and Asia. This scenario is totally unacceptable by any standard. The United Nations Fund for Population Activities Maternal Mortality update focuses on emergency obstetric care, a three-pronged strategic intervention that is fundamental to reducing maternal mortality worldwide. The three-pronged approach includes family planning to ensure that every birth is wanted; skilled care by a health professional during pregnancy and childbirth; and ensuring timely access to care for women experiencing complications. All these three intervention measures can be availed in majority of facilities in this country.

Under poor reproductive health care fall inadequacies in anaesthetic services, emergency obstetric care, treatment of haemorrhages, infection prevention measures, hypertensive disease management in pregnancy, care of obstructed labour and absence of a midwife or doctor at every delivery(1). In developing countries, less than $50 \%$ of all deliveries are attended by skilled staff. In rural Kenya the problem is worsened further by lack or poor transport to move the patients from their homes to the facility, lack of money and lack of permission from the spouse. By the time all these obstacles are overcome it is normally too late(1).

Millennium Development Goal number 5 is to "Improve Maternal Health" and the target is to reduce maternal mortality rate by $75 \%$ between the year 1990 and 2015. Fifteen years have gone by since the goal was set and the question this paper is meant to address is what have we achieved towards this end at facility level at least. At the moment there are no reliable national figures to go by. It is also not realistic to use findings in this study to correlate to what is the picture 
nationally because what is available here in terms of resources cannot be compared with what is on the ground in a remote part of the country. Most of the available literature, however, are from facilities(2-5).

\section{MATERIALS AND METHODS}

This study was carried out at the Kenyatta National Hospital, the main referral institution in this country. Case notes of all maternal deaths during pregnancy, delivery and the puerperium during the study period were perused and data collected. The study design was retrospective descriptive.

The maternal deaths during the study period were determined from the records in the statistics section of the records department. The recovery rate of the files was $80 \%$. Information obtained from the case notes was entered into a precoded questionnaire by the investigator. The questionnaire had sections on sociodemographic characteristics, past obstetrical and gynaecological history, and history of present pregnancy. An attempt was made to compare the findings in this review with findings in previous studies in this area and any change in outcome was noted.

For purposes of this paper, maternal mortality is defined as the death of a woman while pregnant or within 42 days of termination of pregnancy irrespective of the duration and site of the pregnancy, from any cause related to or aggravated by the pregnancy or its management but not from accidental or incidental causes.

Maternal mortality ratio is defined as the number of maternal deaths per 100,000 live births

i.e. maternal deaths $\mathrm{x} 100,000$

Live births

\section{RESULTS}

During the study period there were 27,455 live births and 253 maternal deaths giving a maternal mortality ratio of 921.5 per 100,000 live births. Out of the 253 deaths that occurred only 203 files were retrieved giving a file retrieval rate of $80.2 \%$.

Table 1

Yearly distribution of maternal deaths

\begin{tabular}{lccc}
\hline Year & Deaths & $\begin{array}{c}\text { Live } \\
\text { Births }\end{array}$ & MMR \\
\hline 1995 & 66 & 5,043 & 1308.7 \\
1996 & 80 & 5,519 & 1449.9 \\
1997 & 50 & 5,171 & 966.9 \\
1998 & 36 & 4,725 & 761.9 \\
1999 & 21 & 6,997 & 300.1 \\
\hline Total & 253 & 27,455 & 921.5 \\
\hline
\end{tabular}

In Table 1 there is a sharp rise in maternal mortality rate (MMR) between 1995 and 1996 from 1308 to 1449 respectively, then an apparent decline up to the year 1999 when it is as low as 300.1 per 100,000 .
This is noteworthy especially since in 1999 there were 6997 live births compared to 5043 in 1995 and yet the maternal mortality ratio dropped from 1308.7 to 300.1 per 100,000 a four-fold improvement. Among other reasons, this could mean that after the doctors' strike of 1995, things gradually went back to what they were before the strike $(2,3)$. One would not say it was an improvement as such.

Table 2

Sociodemographic aspects of women who died $(n=203)$

\begin{tabular}{|c|c|c|}
\hline Variable & Frequency & $(\%)$ \\
\hline \multicolumn{3}{|l|}{ Age (years) } \\
\hline $10-19$ & 30 & 14.8 \\
\hline $20-24$ & 87 & 42.9 \\
\hline $25-29$ & 50 & 24.6 \\
\hline $30-34$ & 24 & 11.8 \\
\hline $35-39$ & 9 & 4.4 \\
\hline 40 and above & 2 & 1.0 \\
\hline Unknown & 1 & 0.5 \\
\hline \multicolumn{3}{|l|}{ Educational Level } \\
\hline None & 17 & 8.4 \\
\hline Primary & 120 & 59.1 \\
\hline Post primary & 63 & 31.0 \\
\hline Unknown & 3 & 1.5 \\
\hline \multicolumn{3}{|l|}{ Marital Status } \\
\hline Married & 133 & 65.5 \\
\hline Single & 56 & 27.6 \\
\hline Separated/divorced & 10 & 4.9 \\
\hline Widowed & 3 & 1.5 \\
\hline Unknown & 1 & 0.5 \\
\hline \multicolumn{3}{|l|}{ Occupation } \\
\hline Housewife/Unemployed & 150 & 73.9 \\
\hline Formal Employment & 29 & 14.3 \\
\hline Business & 18 & 8.9 \\
\hline Student & 5 & 2.5 \\
\hline Unknown & 1 & 0.5 \\
\hline
\end{tabular}

Nearly $60 \%$ of the deaths occurred in women aged below 24 years, and $15 \%$ in those below 20 years. $65.5 \%$ of the women who died were married, $27.6 \%$ were single, $4.9 \%$ were divorced and $1.5 \%$ widowed.

Table 3 shows that $78.3 \%$ of deaths occurred among women of parity 2 and below. Postpartum and post abortal complications accounted for $72.4 \%$ of the deaths. Non clinic attendance contributed to $71.5 \%$ of the deaths.

Among the women who attended antenatal clinic (ANC) $34.5 \%$ were nulliparous and $3.4 \%$ were para 5 and above. The difference among the groups was not significant, $\mathrm{p}=0.646$. 
Table 3

Maternal deaths by parity, stage of pregnancy and antenatal clinic attendance

\begin{tabular}{lcc}
\hline & Frequency & $(\%)$ \\
\hline Parity & & \\
0 & 70 & 34.5 \\
1 & 56 & 27.6 \\
2 & 33 & 16.3 \\
3 & 24 & 11.8 \\
4 & 10 & 4.9 \\
5 and above & 6 & 3.0 \\
Unknown & 4 & 2.0 \\
& & \\
Stage of pregnancy & & \\
Antepartum & 34 & 16.7 \\
Intrapartum & 17 & 8.4 \\
Postpartum & 75 & 36.9 \\
Postabortal & 72 & 35.5 \\
Ectopic & 5 & 2.5 \\
Antenatal attendance & & \\
Not attended & & \\
Attended & 128 & 63.1 \\
Unknown & 58 & 28.6 \\
\hline
\end{tabular}

Table 4

Antenatal care versus parity

Antenatal attendance

Yes

No

Total

\begin{tabular}{|c|c|c|c|c|c|c|}
\hline Parity & Frequency & $(\%)$ & Frequency & $(\%)$ & Frequency & $(\%)$ \\
\hline 0 & 20 & 34.5 & 42 & 33.3 & 62 & 33.7 \\
\hline 1 & 17 & 29.3 & 37 & 29.4 & 54 & 29.3 \\
\hline 2 & 12 & 20.7 & 18 & 14.3 & 30 & 16.3 \\
\hline 3 & 6 & 10.3 & 16 & 12.7 & 22 & 12.0 \\
\hline 4 & 1 & 1.7 & 9 & 7.1 & 10 & 5.4 \\
\hline 5 and above & 2 & 3.4 & 4 & 3.2 & 6 & 3.3 \\
\hline Total & 58 & 31.5 & 126 & 68.5 & 184 & 100 \\
\hline
\end{tabular}


Table 5

Causes of maternal mortality

\begin{tabular}{lcc}
\hline Cause of death & No. & $(\%)$ \\
\hline Direct causes (n = 139) & 52 & \\
$\quad$ Postabortal sepsis & 35 & 25.6 \\
Puerperal sepsis & 22 & 17.2 \\
Haemorrhage & 19 & 10.8 \\
Hypertension & 6 & 9.4 \\
Ruptured uterus & 5 & 2.9 \\
Ectopic pregnancy & & 2.5 \\
& & \\
Indirect causes (n $=64)$ & 19 & \\
Pneumonia + PTB & 13 & 9.4 \\
Malaria & 8 & 6.4 \\
HIV/AIDS & 6 & 3.9 \\
Anaemia & 4 & 2.9 \\
Anaesthetic & & 2.0 \\
Complications & 3 & 1.5 \\
Cardiac Disease & 1 & 0.5 \\
Pulmonary embolism & 10 & 4.9 \\
Others & 203 & 100 \\
\hline Total & & \\
\hline
\end{tabular}

Direct obstetric causes of maternal mortality accounted for $68.5 \%$ of maternal deaths out of which sepsis (postabortal and puerperal) amounted to $42.8 \%$ of the total followed by haemorrhage $10.8 \%$. Majority of haemorrhage was postpartum. Eight of the 19 cases with pneumonia and PTB $(42.1 \%)$ tested positive for HIV/AIDS. None of the rest of the patients tested positive.

Of the indirect causes, pneumonia and pulmonary tuberculosis, malaria and HIV/AIDS contributed close to $20 \%$. Eight of the women who had PTB/pneumonia tested positive for HIV/AIDS.

\section{DISCUSSION}

This study shows that the average maternal mortality ratio was 921.5 per 100,000 live births, which is higher than the results of a study done thirty years earlier. One of the reasons that can be advanced for this high rate is the general strike by doctors in the year 1995, and subsequently it took time for their morale to come back and when they eventually resumed work, most of them used to make mere technical appearance. By the year 1999 , things had settled as is reflected by the improved mortality rate of 300.1 per 100,000 , slightly worse than the previous study by Makokha in the same institution (2,3). Between 1972 and 1987, Makokha, in two consecutive reviews from the Kenyatta National Hospital reported an average maternal mortality ratio of 258 per
100,000 live births $(2,3)$. In the first review between 1972 and 1977, he had a figure of 196 per 100,000 and in the next, which was between 1978 and 1987 it was 320 per 100,000 . Compared with our findings and given the fact that we had an unprecedented high mortality associated with the doctors strike and its aftermath, there is some catching up in the later years of the study. It would be worthwhile reviewing the picture between 1999 and now since there is some relative stability. Studies from other hospitals in this country also show very high and unacceptable ratios. Hassan in a study at Kilifi at the Coast of Kenya reported a MMR of 771 per 100,000 (4) and Jaldesa et al (5) reported a rate of 1700 per 100,000 live births at Garissa Provincial Hospital between 1993 and 1995.

These other institutions cannot be fairly compared with our study area mainly because of lack of equipment, poor infrastructure and inadequate trained and skilled personnel. One of the important indicators used to track progress in meeting the "Millennium Development Goal 5 " is the proportion of women who deliver in institutions where there is adequate skilled attendants able to address the complications that may arise (8-11).

Noteworthy is the fact that in spite of skilled care which our patients were purported to have, there are several other confounding factors which could be having a role. These are situations like urban residence, poverty, poor education, inability to attend meaningful antenatal care and birth order. All these factors affected our clients. In the developing countries, Kenya included, percentage of births with skilled attendants increased significantly between the year 1990 and 2000 from $42 \%$ to $52 \%$, but there is nothing to show for it in terms of improved maternal mortality outcome (12-15).

In this study direct obstetric deaths accounted for $68.5 \%$ of all deaths the leading causes of which did not differ much from previous studies done in this institution three decades ago $(2,3)$. Sepsis is still the major cause, and more specifically so postabortal sepsis, which accounted for $25.6 \%$ and puerperal sepsis, which made up $17.2 \%$. Haemorrhage, which in most developing countries is responsible for the highest cause, seems to trail sepsis. Haemorrhage accounted for $10.8 \%$ of all maternal deaths, half of which were due to postpartum haemorrhage, $31.8 \%$ related to abortion and $18.2 \%$ related to antepartum haemorrhage. All women who died of antepartum haemorrhage had been admitted in shock and all attempts at resuscitation were futile. Factors that contributed to death from postpartum haemorrhage included uncontrollable bleeding due to disseminated intravascular coagulopathy in four patients and uterine atony in one patient, all this in spite of blood transfusion. Preventive measures like the use of oxytocics, identification of those at a higher risk and blood transfusion were instituted but the deaths still occurred because of delay in seeking care. 
Among the other direct causes of maternal mortality, ruptured uterus still ranks very high, responsible for 3\% of all deaths. This compares well with studies done before $(2,3)$. This study found that $50 \%$ of the women who ruptured were less than 25 years of age, and majority were Para 2 and below. It was also observed that they mostly came from other health facilities very late in labour such that any resuscitative measures by our institution yielded no positive outcome. Unlike is traditionally believed, it can therefore be inferred that, younger women of low parity stand as much risk of rupture as older high parity women.

The high post abortal sepsis incidence is an indication that management of abortion in this city and the country at large still leaves a large gap, which needs urgent attention if mortality is to be reduced to the level anticipated by the millennium goals. The high incidence of this condition also means that the family planning services are either not being utilised adequately, or are not accessible to the majority of those who need it; or the facilities available are having inadequate supplies of the popular methods. The exact reason needs to be investigated further and necessary measures taken to address the issue. One woman who died from postabortal complications was noted to have disseminated intravascular coagulopathy (DIC). Resuscitative measures including subtotal hysterectomy as an attempt to arrest the postpartum haemorrhage did not help in saving her life.

An increasingly important cause of maternal mortality that did not feature in previous studies from this institution is medical complications related to Human Immunodeficiency Virus (HIV) infections and AIDS. The serostatus of most women at the time of this study was unknown, only $8.4 \%$ of all women having been tested, because voluntary counselling and testing was not mandatory. Indirectly it was noted in this study that pneumonia and pulmonary tuberculosis was responsible for $9.4 \%$ of maternal deaths and $42.1 \%$ of these women tested positive for HIV. Other causes of death amongst the seropositive women were sepsis $23.18 \%$, meningitis in $15.4 \%$, and gastroenteritis in $7.7 \%$.

In comparison, South Africa had seropositivity known in $24.2 \%$ of all maternal deaths and majority of women there who died of AIDS was because of respiratory failure occasioned by overwhelming pneumonia (6).

Deaths from hypertensive disease in pregnancy should largely be preventable by early detection and treatment of hypertension during the antenatal period. It was the third leading cause of death accounting for $9.4 \%$ of all deaths. Most of these deaths occurred among primigravidas who arrived in severe preeclampsia, two of whom died antenatally and one postpartum due to renal failure. These findings are comparable to previous studies in this institution $(2,3)$.

On the socio demographic front, $57.7 \%$ of the women who died were below the age of 24 years;
$67.5 \%$ had attained no more than primary education. The interesting observation is that though $65.5 \%$ were married, $73.9 \%$ were not engaged in any gainful employment or income generating activity. What all this amounts to is that the women are getting married off too young before they are able to complete meaningful education. The early drop off is accompanied by unplanned pregnancy due to idleness and some barriers to family planning, which is very common in this social group $(2,4)$. It was noted that $67.5 \%$ of women who died were in their twenties, $14.8 \%$ below 20 years and only $3.5 \%$ above 35 years. $65.5 \%$ of those who died were married and $63.1 \%$ had not attended any antenatal clinic. $75 \%$ of those who attended clinic started doing so in the second trimester, which is in agreement with the 1993 Kenya Demographic, and Health Survey (7), which found that the median time of first visit was 5.6 months. The other issues which have been shown both locally and internationally to contribute to mortality are the three levels of delay: the first being in seeking care due either to failure to recognise the problem or fear of hospital, or costs; the second delay is due to physical inability caused by lack of transport; and the third delay comes about right in the facility because of poor staffing, prepayment policies, blood unavailability, and delay at the operating theatre.

Addressing the first two delays is of no value if the facility has the above listed inadequacies. Locally and internationally, a three pronged evidence based approach has been shown to work in reducing maternal mortality, and these are family planning, delivery with skilled attendants and emergency basic and comprehensive obstetric care $(15,16)$.

The main limitations of this study are its being retrospective, and being institutional rather than broad countrywide based. Retrospective studies are handicapped by the problem of missing files as shown by this study; and even if the files are available, notes are either not adequate, missing or are not written in a standard structured way.

In conclusion, majority of the maternal deaths occurred among women in the optimum reproductive age and most of them had not attended any antenatal clinic. The main causes of death in this study were sepsis, haemorrhage, hypertensive disease and abortion, the last one of which is the main killer among single women. HIV/AIDS is an important emerging contributor of indirect causes of deaths and it is anticipated it will rise even higher.

We recommend that early effective and appropriate referral system should be put in place to avoid delay and allow for timely intervention. Basic emergency obstetric care for health centres with adequate supply of parenteral fluids, antibiotics and delivery couches and equipment should be the gold standard in our peripheral facilities. The emerging threat and impact of HIV/AIDS on maternal mortality should be addressed adequately. 


\section{REFERENCES}

1. Millennium Development Goals. Maternal health. www.developmentgoals.org. W.H.O.'s Maternal Mortality Rate.

2. Makokha, A.E. Maternal Mortality-KNH 1972-1977. East Afr. Med. J. 1980; 57: 451-460.

3. Makokha, A.E. Medico-social demographic factors associated with maternal mortality at KNH, Nairobi, Kenya. J. Obstet. Gynae. East and Central Afr. 1991; 9: 3-6.

4. Hassan M. Adam. Maternal mortality in Kilifi District 1986-1990. MMed Thesis, University of Nairobi, 1992.

5. Jaldesa, G.W., Qureshi, Z.P., Kigondu, C.S. and Wanjala, S.M. Maternal mortality and morbidity at Garissa Provincial Hospital, a 3 year retrospective survey. J. Obstet. Gynae. East and Central Afr. 1998,14: 68-71.

6. Report on confidential enquiries into maternal deaths in South Africa, 1998.

7. Kenya Demographic and Health Survey, 1993.

8. Freedman, L. Using human rights in maternal mortality programmes. From analysis to strategy. Intern. J. Obstet. Gynae. 2001; 75: 51-60

9. Gill, Z. and Ahmed, J.U. Experience from Bangladesh. Implementing emergency obstetric care as part of reproductive health agenda. Intern. J. Obstet. Gynae. 2004; 85: 213-220.

10. Pan American Health Organisation. Reduction of maternal mortality and morbidity. Interagency strategic consensus for Latin America and the Caribbean. Washington, DC: PAHO. 2003.

11. Scotland, G. and Bullough, C. What do doctors think their caseloads should be in order to maintain their skills for delivery care? Intern. J. Obstet. Gynae. 2004; 7: 301-307.

12. Family Care International. Skilled care during childbirth. Information booklet. New York. FCI.

13. Koblinsky, M.A., Campbell, O. and Heichelhen, J. Organizing delivery care: What works for Safe Motherhood? WHO Bull. 1999; 77: 399-406.

14. Bell, J., Hussein, J., Jeutsch, B.. et al. Improving skilled attendance at delivery. A preliminary report of the SAFE strategy development tool. Birth. 2003; 30: 227-234.

15. Kenya Ministry of Health and UNFPA. Needs Assessment of obstetric fistula in selected districts of Kenya. Final report. Government of Kenya, 2004; page 22.

16. Hussein, J., Goodburn, E.A., Davidson, H. et al. Monitoring obstetric services: Putting the UN guidelines into practice in Malawi, 3 years on. Intern. J. Obstet. Gynae. 2001; 75: 63-73. 